\title{
Immunoglobulin replacement therapy in secondary hypogammaglobulinemia
}

\section{Nicolò Compagno, Giacomo Malipiero, Francesco Cinetto and Carlo Agostini *}

Department of Medicine, Clinical Immunology and Hematology, University of Padova, Padova, Italy

Edited by:

Isabella Quinti, Sapienza University of Rome, Italy

\section{Reviewed by:}

Antonio Condino-Neto, University of São Paulo, Brazil

Hirokazu Kanegane, Tokyo Medical

and Dental University, Japan

\section{*Correspondence:}

Carlo Agostini, Department of

Medicine, Clinical Immunology and

Hematology, University of Padova, Via

Giustiniani 2, Padova 35100, Italy

e-mail: carlo.agostini@unipd.it
Immunoglobulin (Ig) replacement therapy dramatically changed the clinical course of primary hypogammaglobulinemias, significantly reducing the incidence of infectious events. Over the last two decades its use has been extended to secondary antibody deficiencies, particularly those related to hematological disorders as lymphoproliferative diseases (LPDs) and multiple myeloma. In these malignancies, hypogammaglobulinemia can be an intrinsic aspect of the disease or follow chemo-immunotherapy regimens, including anti-CD20 treatment. Other than in LPDs the broadening use of immunotherapy (e.g., rituximab) and immune-suppressive therapy (steroids, sulfasalazine, and mycophenolate mofetil) has extended the occurrence of iatrogenic hypogammaglobulinemia. In particular, in both autoimmune diseases and solid organ transplantation Ig replacement therapy has been shown to reduce the rate of infectious events. Here, we review the existing literature about Ig replacement therapy in secondary hypogammaglobulinemia, with special regard for subcutaneous administration route, a safe, effective, and well-tolerated treatment approach, currently well established in primary immunodeficiencies and secondary hypogammaglobulinemias.

Keywords: immunoglobulin replacement therapy, secondary hypogammaglobulinemia, chronic lymphocytic leukemia, multiple myeloma, bone marrow transplantation, solid organ transplantation, subcutaneous immunoglobulins

\section{INTRODUCTION}

Immunoglobulins (Ig) have been commercially available since the 1940 s, and first carried out as replacement therapy (IgRT) in a patient with agammaglobulinemia in 1951 by Ogden Bruton. From that first experience on, Ig have been widely used in patients with primary immune deficiency (PID), as it is well known that hypogammaglobulinemia is a crucial risk factor for development of infectious events and IgRT is able to reduce this risk. By contrast, the lack of clear indications regarding the use of prophylactic IVIG in secondary antibody deficiencies (SAD) may appear paradoxical, if we consider the broad range of disorders in which hypogammaglobulinemia is an intrinsic aspect of the disease or a iatrogenic consequence (Table 1) and being the number of affected patients significantly higher than in PID.

In this review, we summarize the most common conditions in which SAD can be observed. We also describe evidence indicating the possibility of subcutaneous (SCIG) rather than intravenous (IVIG) Ig for the treatment for SAD.

\section{CHRONIC LYMPHOCYTIC LEUKEMIA}

Infective complications account for up to $50 \%$ of all chronic lymphocytic leukemia (CLL)-related deaths (1). Their etiology is multifactorial, due to disease-related immune defects and/or chemo-immunotherapy treatment regimens $(2,3)$. Hypogammaglobulinemia is the most common chronic immune defect in patients with CLL (the prevalence ranges from 20 to $70 \%$ ), and correlates with duration and stage of the disease (4). The defect is usually irreversible even in patients achieving complete disease remission. A direct relationship was found between low levels of IgG and the frequency/severity of infections.

Two main strategies are indicated in UK guidelines for patients with hypogammaglobulinemia who develop recurrent bacterial infections (1): antibiotic prophylaxis and IgRT. Nonetheless, there are no standard guidelines for antimicrobial prophylaxis in CLL patients, and most recommendations are derived from small clinical trials and anecdotal reports $(4,5)$.

Regarding prophylactic IVIG in patients with CLL and hypogammaglobulinemia, randomized controlled studies have been performed in the 1980s ad 1990s and recently summarized (6): they suggest that the use of IVIG may be considered in patients with hypogammaglobulinemia secondary to CLL who experience recurrent infections, since IVIG could significantly decrease the number of infections and the use of antibiotics, reducing hospitalization need and loss of working days. Despite this, the authors did not found any difference in all cause mortality between the treated and control group, maybe due to the relatively short follow-up time ( 1 year). For these reasons, according to UK guidelines IgRT indicated in patients with a serum $\operatorname{IgG}<500 \mathrm{mg} / \mathrm{dl}$ complaining of recurrent or severe infections (1). Similar indications are suggested in the Canadian guidelines (7) and by the panel group of the Primary Immunodeficiency Committee of the American Academy of Allergy, Asthma, and Immunology (8). In all these guidelines, an initial dose of $400 \mathrm{mg} / \mathrm{kg}$ administered intravenously 3-4 weekly is suggested, aiming at a trough level of $600-800 \mathrm{mg} / \mathrm{dl}(1,7)$. The Ig dose should be then adjusted according to clinical response and steady state trough levels (IgG trough level $>400 \mathrm{mg} / \mathrm{dl}$ ). As 
in PID, higher trough levels may be beneficial in patients with underlying co-morbidities, particularly bronchiectasis. On the basis of these evidences and our experience (9), the same indications are followed in our outpatient clinic. We regularly evaluate the response to IgRT after 12 months, to assess its efficacy and to judge the need of continuing or stopping the infusions.

Attempts have been made to define the risk factors for infections in CLL, in order to select patients who could benefit from IgRT even with a pre-emptive approach. In two papers $(10,11)$, factors other than Ig concentration (previous chemotherapy, clinical stage, CD38 expression, genetic analysis, and IgVH mutations) have been pointed out as the main prognostic markers for the development of infections, while low IgG level seem not to be clearly associated with infections. Nonetheless, in these studies IgG levels were recorded independently from infectious events, at diagnosis or at the moment of the survey. In CLL, hypogammaglobulinemia is commonly progressive over time; thus, IgG levels evaluated at onset of the disease may significantly differ from levels observed at the time of infection onset. Dhalla et al. (12) suggested that immunization responses could be used to stratify infection risk and select patients for IgRT, but caution is recommend since interpreting immunization assays is complex, cut-off levels may vary and there are controversies in stating what constitutes an adequate response. Finally, Freeman et al. (13) suggested that screening patients with CLL for IgG subclass deficiency may be a useful adjunct in stratifying their risk for infection, since they were able to show a significant relationship between any IgG subclass deficiency and infections, regardless of the total Ig level.

\section{MULTIPLE MYELOMA}

Infection is a significant cause of morbidity and the leading cause of death in patients with multiple myeloma (MM) (14). The increased susceptibility to infections results from the interplay between antineoplastic therapies and disease-related complications (15). Moreover, novel treatments significantly prolonged survival transforming MM into a chronic condition, characterized by multiple relapses and salvage therapies, resulting in an increased cumulative immunosuppression and a higher risk for infection. The incidence of infectious events varies in different phases of MM (16), and seems to be higher during active disease and in the first months of induction chemotherapy. In early-stage $\mathrm{MM}$, the most common infections involve the respiratory tract, manifesting as bronchitis and pneumonia. These infections are

Table 1 | Main causes of secondary hypogammaglobulinemia.

\begin{tabular}{ll}
\hline Secondary hypogammaglobulinemia & \\
\hline Excessive loss of immunoglobulins & $\begin{array}{l}\text { Protein-losing enteropathy } \\
\text { Nephrotic syndrome } \\
\end{array}$ \\
& Severe burns \\
Malignancy & Chronic lymphocytic leukemia \\
& Multiple myeloma \\
& Good's syndrome \\
& Non-Hodgkin B cell lymphomas \\
Drug induced & See Table 2
\end{tabular}

predominantly caused by $H$. influenzae or S. pneumonia, suggesting a role of hypogammaglobulinemia in their pathogenesis. In patients with advanced disease and during the neutropenic phases of intensive chemotherapy, S. aureus and gram-negative bacteria are more common, thus implying different underlying pathogenic mechanisms.

As in CLL, only few studies evaluated the role of IgRT in patients with hypogammaglobulinemia and MM. Chapel et al. (17) in 1994 performed a randomized, double-blind, placebo-controlled, multicenter trial of IVIG employed as prophylaxis against infection in 82 patients with stable MM; the authors demonstrated a protective role of IVIG against life-threatening infections and a significant role in reducing the risk of recurrent infections. Other two studies have been performed in patients with hypogammaglobulinemia and either CLL or MM, obtaining similar results (6). Conversely, Blombery et al. (18) showed no benefit of the use of peritransplant IVIG to reduce infectious complications in hypogammaglobulinemic patients with MM undergoing autologous stem cell transplantation.

In our opinion, regular Ig substitution should be considered in MM patients who suffer from life-threatening or recurrent infections that are reasonably thought to be caused by low levels of polyclonal Ig $(16,19)$. Similar indications are suggested in the Canadian guidelines about IgRT (7), where the proposed regimen consists of $400 \mathrm{mg} / \mathrm{kg}$ of IVIG administered every 4 weeks, subsequently adjusted to reach an individualized "biological" trough level. Prophylactic therapy with Ig during autologous stem cell transplantation is not recommended. Unfortunately, we observed that it may be not so easy to exactly define the level of polyclonal Ig in patients with $\mathrm{MM}$, due to the presence of the monoclonal protein that interfere with Ig determinations. We suggest that clinical evaluation and anamnestic aspects are fundamental to decide if may be helpful to prescribe or not substitutive therapy in MM.

\section{IATROGENIC HYPOGAMMAGLOBULINEMIA}

As shown in Table 2, pharmacological history of the patient should be carefully evaluated when hypogammaglobulinemia is detected.

One of the most used drug able to induce iatrogenic hypogammaglobulinemia is the anti-CD20 monoclonal antibody

Table 2 | Main causes of drug-induced hypogammaglobulinemia.

\section{Drug-induced hypogammaglobulinemia}

Anti B cells monoclonal antibodies

Immunosuppressants and chemotherapeutics

TKI inhibitors

Anticonvulsants

Others (sporadically described)
Rituximab

Belimumab

Steroids

Gold salts

Azathioprine

Imatinib

Dasatinib

Carbamazepine

Valproate

Ramipril

Acetylsalicylic acid 
rituximab. Firstly experimented and introduced in the clinical practice for the treatment of hematological malignancies, it has become a commonly used immune modulatory strategy for the treatment of many refractory or poorly controlled autoimmune or inflammatory disorders. Removal of CD20-expressing cell populations induces a dysregulation of immune homeostasis, impacting regulatory functions of normal B cells (20, 21). Hypogammaglobulinemia represents common negative consequences of this imbalance (22-27), and is considered the main factor that influences the increased risk of infection in patients receiving rituximab (28-30). According to recent hypotheses (31-33), a subgroup of rituximab-induced hypogammaglobulinemias should be considered as the consequence of the presence of a latent PID. In some cases, rituximab would elicit the antibody defect in genetically predisposed individuals (34).

Kelesidis et al. (35) recently summarized the available evidence about rituximab use and infections: the risk was increased in patients with hematological malignancies, while in patients with autoimmune diseases the risk was similar to other treatments. However, considering the number of confounders potentially masking or modulating the overall effects (e.g., co-morbidities, concurrent chemotherapy, presence of neutropenia, number of rituximab cycles, etc.), caution has been suggested in drawing definitive conclusions. In hematological conditions, the incidence of transient or persistent hypogammaglobulinemia following rituximab-therapy ranges from 15 to $40 \%$ (28). Female gender, fludarabine association regimens (36), and administration after autologous stem cell transplantation (37-40) have been identified as main risks factors, while maintenance therapy for follicular lymphoma is associated with a very low incidence of hypogammaglobulinemia (41). Regarding autoimmune disorders, two recent studies described a possible detrimental effects of rituximab on Ig synthesis in patients with ANCA-associated vasculitides (42, 43), and in particular in patients relapsing after cyclophosphamide treatment (43). Conversely, other studies contradict these observations: Marco et al. (44) reported that hypogammaglobulinemia could be attributed to the prior cyclophosphamide/steroid exposure rather than to the cumulative rituximab dose. Finally, the risk of hypogammaglobulinemia and infections seems to be related to the underlying autoimmune condition: in patients with rheumatoid arthritis or immune thrombocytopenia, the treatment is well-tolerated without significant risk of infections and hypogammaglobulinemia $(22,45-47)$.

We suggest that Ig levels should be always checked before rituximab administration and monitored for at least 6 months after the last dose. A longer period of observation should be addressed in patients presenting with low Ig levels prior to rituximab-therapy or in those who show risk factors for prolonged/severe hypogammaglobulinemia. In any case prompted IgRT should be offered, either e.v. or subcutaneous, to those patients who complain severe or recurrent infection episodes and concomitant low Ig levels.

\section{BONE MARROW TRANSPLANTATION}

Allogeneic bone marrow transplantation (ASCT) is a well established therapy in hematological malignancies. Immune defects are common consequences, persisting for years after ASCT. Arai et al. (48) recently described that the cumulative incidence of hypogammaglobulinemia $(\mathrm{IgG}<400 \mathrm{mg} / \mathrm{dl})$ in a cohort of 278 patients was 24.1 or $27.1 \%$, respectively 1 or 3 years after ASCT. Risk factors were lymphoid malignancies, history of previous ASCT, usage of mycophenolate mofetil, low pre-ASCT IgG levels, and grade 2-4 aGVHD. Norlin et al. (49) described that patients with low IgG levels $(<400 \mathrm{mg} / \mathrm{dl})$ had an increased risk of transplant-related mortality compared to patients with moderately low or normal levels. Patients with low IgG levels had an increased incidence of infections as cause of death.

A recent meta-analysis (6) summarizes data on IgRT in patients undergone ASCT. When polyvalent Ig or hyperimmune cytomegalovirus CMV-IVIG are compared, there are no differences in mortality, rate of infections, CMV infections, and microbiologically documented infections. Polyvalent Ig significantly reduced the risk for interstitial pneumonitis but increased the risk for veno-occlusive disease and adverse events. Moreover, guidelines for preventing infectious complications provided by the American Society of Bone Marrow Transplantation (50) suggest that benefit is small if IVIG are used for prophylaxis of bacterial infections in patients with severe hypogammaglobulinemia (defined by authors as $\operatorname{IgG}<400 \mathrm{mg} / \mathrm{dL}$ ). The panel of experts recommends that IVIG dose and frequency should be individualized to maintain trough serum IgG concentrations $>400 \mathrm{mg} / \mathrm{dL}$. Again, IVIG are not recommended for CMV-disease prophylaxis after ASCT. Interestingly, Sundin et al. (51) showed that SCIG therapy is as effective as IVIG in maintaining IgG levels above $400 \mathrm{mg} / \mathrm{dl}$ in pediatric patients after ASCT, and SCIG were associated to less adverse events compared to IVIG.

\section{SOLID ORGAN TRANSPLANTATION}

Hypogammaglobulinemia has been reported as a complication of solid organ transplantation, particularly after heart, lung, and kidney transplantation, with an associated increased risk for infections. Moderate to severe hypogammaglobulinemia in recipients of lung transplantation has been associated with increased occurrence of infections, longer hospitalization, and acute cellular rejection. Hypogammaglobulinemia appeared to be related to 1-year all cause mortality. A recent meta-analysis by Florescu et al. (52) found a consistent prevalence of hypogammaglobulinemia (45\%) and severe hypogammaglobulinemia (15\%) during the first posttransplant year. The risk of infections was higher (2.46-fold) when IgG were less than $400 \mathrm{mg} / \mathrm{dL}$; the risk of infections in patients with IgG $>400 \mathrm{mg} / \mathrm{dL}$ did not differ with respect to patients with normal Ig levels. This risk is related to the immune-suppressive treatment, being particularly high if mycophenolate mofetil is employed.

Concerning the role of IgRT in transplanted patients with hypogammaglobulinemia it has been reported that IgRT favors the reduction of infections rate $(53,54)$. Moreover, a single center experience (55) suggested that SCIG replacement therapy represents a well-tolerated alternative to IVIG after lung transplantation. Unfortunately, these studies are heterogeneous in terms of study populations or/and criteria of inclusion/exclusion for the beginning of IgRT and definitive conclusion cannot be drawn. Anyway, we suggest to start IgRT in patients with severe hypogammaglobulinemia, or in patients who complain recurrent infections reasonably related to low IgG levels. The proposed starting 
regimen should be $400 \mathrm{mg} / \mathrm{kg}$ of IVIG administered every 4 weeks, subsequently adjusted to reach an individualized "biological" trough level.

\section{OTHER CAUSES OF SECONDARY HYPOGAMMAGLOBULINEMIA}

Conditions that frequently cause Ig loss include burns, renal, or intestinal diseases. Protein-losing enteropathy is characterized by an excessive loss of proteins into the gastrointestinal tract, resulting in some cases in symptomatic hypogammaglobulinemia. An hypoproteinemic state with hypogammaglobulinemia can be also a consequence of severe burns. Treatment of these disorders consists mainly in the management of the underlying disease, and no extensive data are available regarding IgRT.

A variety of infections has been recognized as an important cause of morbidity and mortality in patients with nephrotic syndrome. Immune defects in these patients are due to edema complications, urinary loss of complement factors and Ig, and defects in cellular immunity and secondary effects of immunosuppressive therapy. Many different prophylactic interventions have been used for reducing the risks of infection in these patients but recommendations for routine use are still lacking (56).

Hypogammaglobulinemia is present in a small percentage of patients with thymoma (Good's syndrome), usually symptomatic. Often, hypogammaglobulinemia persists after the treatment of the underlying disease. There are some reports on the efficacy of IgRT in these patients $(57,58)$.

\section{HIV INFECTION}

HIV infection is peculiar in its immunological profile. Patients usually exhibited hypergammaglobulinemia that encompassed all three Ig classes, but given the $\mathrm{T}$ cell defect they failed to mount specific antibody responses to various $\mathrm{T}$ cell dependent antigens, and in particular encapsulated bacteria (59). In adults with HIV, opportunistic infections are the most common manifestations of the immune deficiency; instead, children frequently experience a different immunological impairment, complaining of recurrent serious bacterial infections (bacteremia and pneumonia) (60).

On the basis of the results obtained in the NICHHD trials in 1991 (61) and several smaller studies previously performed, IVIG have been approved for preventing invasive bacterial infections in children with HIV infection ( $400 \mathrm{mg} / \mathrm{kg}$ every $2-4$ weeks). IVIG seems to have only limited therapeutic benefit in terms of mortality reduction in the acute phase of the bacterial infections (60). The utility of IgRT has been later questioned, because antibiotic prophylaxis and especially retroviral therapy have dramatically changed the clinical course of the disease (60); nowadays IgRT is taken into account only in selective cases with recurrent bacterial infections despite antiretroviral and antibiotic therapy.

Adult patients with HIV may retain their full complement of B cells, and are less susceptible to infections with common pathogens, even if HIV can profoundly affect humoral immunity in a subset of patients. Several uncontrolled trials did not shown conclusive benefits to routine IgRT (59). These studies should not exclude the use of IVIG for adults who are infected with HIV-1 with recurrent bacterial infections despite antiretroviral and antibiotic therapy.

\section{SUBCUTANEOUS IMIMUNOGLOBULINS}

Subcutaneous Ig have been widely shown to be safe, cost-effective, and greatly appreciated in terms of Health-Related Quality of Life (HRQL) in patients with PID (62-66). SCIG can be self administered at home, do not require venous access and systemic premedication, are characterized by a gradual absorption of the drug and by a decrease in the incidence of systemic adverse effects $(66,67)$. Local reactions are usually mild and do not affect the good tolerability of the treatment (68).

Safety and efficacy of SCIG in SAD have been assessed in few case series. We showed that SCIG are safe and effective in maintaining adequate levels of serum IgG in patients with lymphoproliferative diseases (LPDs) and hypogammaglobulinemia (9). We also observed an improvement perceived in HRQL. Similar results in term of efficacy, safety, and HRQL were obtained in children after hematopoietic stem cell transplantation (51) and in patients after lung transplantation (55).

Other potential benefits of SCIG should be considered in patients with hematological malignancies. Venous access often represents a great concern after chemotherapy treatments, and SCIG provide the possibility to avoid the use of venous accesses. The flexibility of SCIG treatment and the possibility of a homebased infusion represent a further advance for patients who usually need an high number of outpatient visits.

\section{OPEN QUESTIONS}

In this review, evidence has been provided suggesting that IgRT is effective in most patients with SAD. Nonetheless, cost-effectiveness advantage of initiating an IgRT in subjects with SAD has been criticized by some authors. To provide a conclusive reply to this criticism, a question should be definitively answered by future studies: what criteria should be used to identify patients in whom prophylactic IgRT may help to decrease infectious risk? At present IgG levels represent the only parameter employed to this aim. A better selection of patients in which IgRT is needed can lead us to limit the perhaps too extended use of IgRT in SAD.

\section{AUTHOR CONTRIBUTIONS}

All the authors participate in the definition of the work. Nicolò Compagno, Giacomo Malipiero, and Francesco Cinetto prepared the manuscript. Carlo Agostini coordinated the work and critically revised the manuscript. The final version of this work was approved by all authors.

\section{REFERENCES}

1. Oscier D, Dearden C, Eren E, Erem E, Fegan C, Follows G, et al. Guidelines on the diagnosis, investigation and management of chronic lymphocytic leukaemia. $\mathrm{Br}$ J Haematol (2012) 159:541-64. doi:10.1111/bjh.12067

2. Ravandi F, O'Brien S. Immune defects in patients with chronic lymphocytic leukemia. Cancer Immunol Immunother (2006) 55(2):197-209. doi:10.1007/ s00262-005-0015-8

3. Sinisalo M, Aittoniemi J, Koski T, Tobin G, Thunberg U, Sundstrom C, et al. Similar humoral immunity parameters in chronic lymphocytic leukemia patients independent of VH gene mutation status. Leuk Lymphoma (2004) 45(12):2451-4. doi:10.1080/10428190400007763

4. Morrison VA. Infectious complications of chronic lymphocytic leukaemia: pathogenesis, spectrum of infection, preventive approaches. Best Pract Res Clin Haematol (2010) 23:145-53. doi:10.1016/j.beha.2009.12.004 
5. Egerer G, Hensel M, Ho AD. Infectious complications in chronic lymphoid malignancy. Curr Treat Options Oncol (2001) 2:237-44. doi:10.1007/s11864001-0037-1

6. Raanani P, Paul M, Leibovici L, Shpilberg O. Immunoglobulin prophylaxis in hematological malignancies and hematopoietic stem cell transplantation. Cochrane Database Syst Rev (2008) (4):CD006501. doi:10.1002/14651858. CD006501.pub2.

7. Anderson D, Ali K, Blanchette V, Brouwers M, Couban S, Radmoor P, et al. Guidelines on the use of intravenous immune globulin for hematologic conditions. Transfus Med Rev (2007) 21:S9-56. doi:10.1016/j.tmrv.2007.01.001

8. Orange JS, Hossny EM, Weiler CR, Ballow M, Berger M, Bonilla FA, et al. Use of intravenous immunoglobulin in human disease: a review of evidence by members of the Primary Immunodeficiency Committee of the American Academy of Allergy, Asthma and Immunology. J Allergy Clin Immunol (2006) 117:S525-53. doi:10.1016/j.jaci.2006.01.015

9. Compagno N, Cinetto F, Semenzato G, Agostini C. Subcutaneous immunoglobulin in lymphoproliferative disorders and rituximab-related secondary hypogammaglobulinemia: a single-center experience in 61 patients. Haematologica (2014) 99(6):1101-6. doi:10.3324/haematol.2013.101261

10. Francis S, Karanth M, Pratt G, Starczynski J, Hooper L, Fegan C, et al. The effect of immunoglobulin $\mathrm{VH}$ gene mutation status and other prognostic factors on the incidence of major infections in patients with chronic lymphocytic leukemia. Cancer (2006) 107:1023-33. doi:10.1002/cncr.22094

11. Hensel M, Kornacker M, Yammeni S, Egerer G, Ho AD. Disease activity and pretreatment, rather than hypogammaglobulinaemia, are major risk factors for infectious complications in patients with chronic lymphocytic leukaemia. $\mathrm{Br} \mathrm{J}$ Haematol (2003) 122:600-6. doi:10.1046/j.1365-2141.2003.04497.x

12. Dhalla F, Lucas M, Schuh A, Bhole M, Jain R, Patel SY, et al. Antibody deficiency secondary to chronic lymphocytic leukemia: should patients be treated with prophylactic replacement immunoglobulin? J Clin Immunol (2014) 34(3):277-82. doi:10.1007/s10875-014-9995-5

13. Freeman JA, Crassini KR, Best OG, Forsyth CJ, Mackinlay NJ, Han P, et al. Immunoglobulin $\mathrm{G}$ subclass deficiency and infection risk in 150 patients with chronic lymphocytic leukemia. Leuk Lymphoma (2013) 54:99-104. doi:10.3109/ 10428194.2012.706285

14. Nucci M, Anaissie E. Infections in patients with multiple myeloma in the era of high-dose therapy and novel agents. Clin Infect Dis (2009) 49(8):1211-25. doi:10.1086/605664

15. Kyrtsonis MC, Mouzaki A, Maniatis A. Mechanisms of polyclonal hypogammaglobulinaemia in multiple myeloma (MM). Med Oncol (1999) 16(2):73-7. doi:10.1007/BF02785839

16. Ludwig H, Zojer N. Supportive care in multiple myeloma. Best Pract Res Clin Haematol (2007) 20(4):817-35. doi:10.1016/j.beha.2007.10.001

17. Chapel HM, Lee M, Hargreaves R, Pamphilon DH, Prentice AG. Randomised trial of intravenous immunoglobulin as prophylaxis against infection in plateauphase multiple myeloma. The UK Group for Immunoglobulin Replacement Therapy in Multiple Myeloma. Lancet (1994) 343(8905):1059-63. doi:10.1016/ S0140-6736(94)90180-5

18. Blombery P, Prince HM, Worth LJ, Main J, Yang M, Wood EM, et al. Prophylactic intravenous immunoglobulin during autologous haemopoietic stem cell transplantation for multiple myeloma is not associated with reduced infectious complications. Ann Hematol (2011) 90(10):1167-72. doi:10.1007/s00277-0111275-3

19. Snowden JA, Ahmedzai SH, Ashcroft J, D'Sa S, Littlewood T, Low E, et al. Guidelines for supportive care in multiple myeloma 2011. Br J Haematol (2011) 154(1):76-103. doi:10.1111/j.1365-2141.2011.08574.x

20. Avivi I, Stroopinsky D, Katz T. Anti-CD20 monoclonal antibodies: beyond Bcells. Blood Rev (2013) 27(5):217-23. doi:10.1016/j.blre.2013.07.002

21. Kano G, Nakatani T, Yagi K, Sakamoto I, Imamura T. Complicated pathophysiology behind rituximab-induced persistent hypogammaglobulinemia. Immunol Lett (2014) 159(1-2):76-8. doi:10.1016/j.imlet.2013.10.005

22. Cooper N, Davies EG, Thrasher AJ. Repeated courses of rituximab for autoimmune cytopenias may precipitate profound hypogammaglobulinaemia requiring replacement intravenous immunoglobulin. Br J Haematol (2009) 146(1):120-2. doi:10.1111/j.1365-2141.2009.07715.x

23. De La Torre I, Leandro MJ, Valor L, Becerra E, Edwards JC, Cambridge G. Total serum immunoglobulin levels in patients with RA after multiple B-cell depletion cycles based on rituximab: relationship with B-cell kinetics. Rheumatology (2012) 51(5):833-40. doi:10.1093/rheumatology/ker417
24. Levy R, Mahevas M, Galicier L, Boutboul D, Moroch J, Loustau V, et al. Profound symptomatic hypogammaglobulinemia: a rare late complication after rituximab treatment for immune thrombocytopenia. Report of 3 cases and systematic review of the literature. Autoimmun Rev (2014) 13(10):1055-63. doi:10.1016/j.autrev.2014.08.036

25. Makatsori M, Kiani-Alikhan S, Manson AL, Verma N, Leandro M, Gurugama NP, et al. Hypogammaglobulinaemia after rituximab treatment-incidence and outcomes. QJM (2014) 107(10):821-8. doi:10.1093/qjmed/hcu094

26. Miles SA, McGratten M. Persistent panhypogammaglobulinemia after CHOPrituximab for HIV-related lymphoma. J Clin Oncol (2005) 23(1):247-8. doi:10. 1200/JCO.2005.05.282

27. Nishio M, Endo T, Fujimoto K, Sato N, Sakai T, Obara M, et al. Persistent panhypogammaglobulinemia with selected loss of memory $\mathrm{B}$ cells and impaired isotype expression after rituximab therapy for post-transplant EBVassociated autoimmune hemolytic anemia. Eur J Haematol (2005) 75(6):527-9. doi:10.1111/j.1600-0609.2005.00552.x

28. Casulo C, Maragulia J, Zelenetz AD. Incidence of hypogammaglobulinemia in patients receiving rituximab and the use of intravenous immunoglobulin for recurrent infections. Clin Lymphoma Myeloma Leuk (2013) 13(2):106-11. doi:10.1016/j.clml.2012.11.011

29. Duraisingham SS, Buckland M, Dempster J, Lorenzo L, Grigoriadou S, Longhurst HJ. Primary vs. secondary antibody deficiency: clinical features and infection outcomes of immunoglobulin replacement. PLoS One (2014) 9(6):e100324. doi:10.1371/journal.pone.0100324

30. Kanbayashi Y, Nomura K, Fujimoto Y, Yamashita M, Ohshiro M, Okamoto K, et al. Risk factors for infection in haematology patients treated with rituximab. Eur J Haematol (2009) 82(1):26-30. doi:10.1111/j.1600-0609.2008.01165.x

31. Diwakar L, Gorrie S, Richter A, Chapman O, Dhillon P, Al-Ghanmi F, et al. Does rituximab aggravate pre-existing hypogammaglobulinaemia? J Clin Pathol (2010) 63(3):275-7. doi:10.1136/jcp.2009.068940

32. Kaplan B, Kopyltsova Y, Khokhar A, Lam F, Bonagura V. Rituximab and immune deficiency: case series and review of the literature. J Allergy Clin Immunol Pract (2014) 2(5):594-600. doi:10.1016/j.jaip.2014.06.003

33. Mogensen TH, Bernth-Jensen JM, Petersen CC, Petersen MS, Nyvold C, Gadegaard $\mathrm{KH}$, et al. Common variable immunodeficiency unmasked by treatment of immune thrombocytopenic purpura with rituximab. BMC Hematol (2013) 13(1):4. doi:10.1186/2052-1839-13-4

34. Nishio M, Endo T, Fujimoto K, Yamamoto S, Obara M, Yamaguchi K, et al. FCGR3A-158V/F polymorphism may correlate with the levels of immunoglobulin in patients with non-Hodgkin's lymphoma after rituximab treatment as an adjuvant to autologous stem cell transplantation. Eur J Haematol (2009) 82(2):143-7. doi:10.1111/j.1600-0609.2008.01174.x

35. Kelesidis T, Daikos G, Boumpas D, Tsiodras S. Does rituximab increase the incidence of infectious complications? A narrative review. Int J Infect Dis (2011) 15(1):e2-16. doi:10.1016/j.ijid.2010.03.025

36. Cabanillas F, Liboy I, Pavia O, Rivera E. High incidence of non-neutropenic infections induced by rituximab plus fludarabine and associated with hypogammaglobulinemia: a frequently unrecognized and easily treatable complication. Ann Oncol (2006) 17(9):1424-7. doi:10.1093/annonc/mdl141

37. Imashuku S, Teramura T, Morimoto A, Naya M, Kuroda H. Prolonged hypogammaglobulinemia following rituximab treatment for post transplant Epstein-Barr virus-associated lymphoproliferative disease. Bone Marrow Transplant (2004) 33(1):129-30. doi:10.1038/sj.bmt.1704307

38. Lim SH, Zhang Y, Wang Z, Esler WV, Beggs D, Pruitt B, et al. Maintenance rituximab after autologous stem cell transplant for high-risk B-cell lymphoma induces prolonged and severe hypogammaglobulinemia. Bone Marrow Transplant (2005) 35(2):207-8. doi:10.1038/sj.bmt.1704742

39. Shortt J, Spencer A. Adjuvant rituximab causes prolonged hypogammaglobulinaemia following autologous stem cell transplant for non-Hodgkin's lymphoma. Bone Marrow Transplant (2006) 38(6):433-6. doi:10.1038/sj.bmt. 1705463

40. Nishio M, Fujimoto K, Yamamoto S, Endo T, Sakai T, Obara M, et al. Hypogammaglobulinemia with a selective delayed recovery in memory B cells and an impaired isotype expression after rituximab administration as an adjuvant to autologous stem cell transplantation for non-Hodgkin lymphoma. Eur J Haematol (2006) 77(3):226-32. doi:10.1111/j.1600-0609.2006.00693.x

41. Witzens-Harig M, Foa R, Di Rocco A, van Hazel G, Chamone DF, Rowe JM, et al. Maintenance with rituximab is safe and not associated with severe or uncommon infections in patients with follicular lymphoma: results from the 
phase IIIb MAXIMA study. Ann Hematol (2014) 93(10):1717-24. doi:10.1007/ s00277-014-2103-3

42. Besada E, Koldingsnes W, Nossent JC. Long-term efficacy and safety of preemptive maintenance therapy with rituximab in granulomatosis with polyangiitis: results from a single centre. Rheumatology (2013) 52(11):2041-7. doi:10. 1093/rheumatology/ket257

43. Venhoff N, Effelsberg NM, Salzer U, Warnatz K, Peter HH, Lebrecht D, et al. Impact of rituximab on immunoglobulin concentrations and $\mathrm{B}$ cell numbers after cyclophosphamide treatment in patients with ANCA-associated vasculitides. PLoS One (2012) 7(5):e37626. doi:10.1371/journal.pone.0037626

44. Marco H, Smith RM, Jones RB, Guerry MJ, Catapano F, Burns S, et al. The effect of rituximab therapy on immunoglobulin levels in patients with multisystem autoimmune disease. BMC Musculoskelet Disord (2014) 15:178. doi:10.1186/1471-2474-15-178

45. van Vollenhoven RF, Emery P, Bingham CO III, Keystone EC, Fleischmann RM, Furst DE, et al. Long-term safety of rituximab in rheumatoid arthritis: 9.5-year follow-up of the global clinical trial programme with a focus on adverse events of interest in RA patients. Ann Rheum Dis (2013) 72(9):1496-502. doi:10.1136/annrheumdis-2012-201956

46. Zaja F, Volpetti S, Chiozzotto M, Puglisi S, Isola M, Buttignol S, et al. Long-term follow-up analysis after rituximab salvage therapy in adult patients with immune thrombocytopenia. Am J Hematol (2012) 87(9):886-9. doi:10.1002/ajh.23272

47. Arnold DM, Dentali F, Crowther MA, Meyer RM, Cook RJ, Sigouin C, et al. Systematic review: efficacy and safety of rituximab for adults with idiopathic thrombocytopenic purpura. Ann Intern Med (2007) 146(1):25-33. doi:10.7326/ 0003-4819-146-1-200701020-00006

48. Arai Y, Yamashita K, Mizugishi K, Kondo T, Kitano T, Hishizawa M, et al. Risk factors for hypogammaglobulinemia after allo-SCT. Bone Marrow Transplant (2014) 49(6):859-61. doi:10.1038/bmt.2014.28

49. Norlin AC, Sairafi D, Mattsson J, Ljungman P, Ringden O, Remberger M. Allogeneic stem cell transplantation: low immunoglobulin levels associated with decreased survival. Bone Marrow Transplant (2008) 41(3):267-73. doi:10.1038/ sj.bmt.1705892

50. Tomblyn M, Chiller T, Einsele H, Gress R, Sepkowitz K, Storek J, et al. Guidelines for preventing infectious complications among hematopoietic cell transplantation recipients: a global perspective. Biol Blood Marrow Transplant (2009) 15(10):1143-238. doi:10.1016/j.bbmt.2009.06.019

51. Sundin M, Nordin K, Jostemyr Y, Winiarski J. Subcutaneous IgG replacement after pediatric SCT. Pediatr Transplant (2012) 16(8):866-71. doi:10.1111/j.13993046.2012.01783.x

52. Florescu DF, Kalil AC, Qiu F, Schmidt CM, Sandkovsky U. What is the impact of hypogammaglobulinemia on the rate of infections and survival in solid organ transplantation? A meta-analysis. Am J Transplant (2013) 13(10):2601-10. doi:10.1111/ajt.12401

53. Carbone J, Sarmiento E, Del Pozo N, Rodriguez-Molina JJ, Navarro J, FernandezYanez J, et al. Restoration of humoral immunity after intravenous immunoglobulin replacement therapy in heart recipients with post-transplant antibody deficiency and severe infections. Clin Transplant (2012) 26(3):E277-83. doi:10. 1111/j.1399-0012.2012.01653.x

54. Yamani MH, Avery R, Mawhorter S, Young JB, McNeill A, Cook DJ, et al. Hypogammaglobulinemia after heart transplantation: impact of pre-emptive use of immunoglobulin replacement (CytoGam) on infection and rejection outcomes. Transpl Infect Dis (2001) 3(Suppl 2):40-3. doi:10.1034/j.1399-3062. 2001.00008.x

55. Shankar T, Gribowicz J, Crespo M, Silveira FP, Pilewski J, Petrov AA. Subcutaneous IgG replacement therapy is safe and well tolerated in lung transplant recipients. Int Immunopharmacol (2013) 15(4):752-5. doi:10.1016/j.intimp.2013.02. 021

56. Molinaro I, Barbano B, Rosato E, Cianci R, Di Mario F, Quarta S, et al. Safety and infectious prophylaxis of intravenous immunoglobulin in elderly patients with membranous nephropathy. Int J Immunopathol Pharmacol (2014) 27(2): 305-8.
57. Fijolek J, Wiatr E, Demkow U, Orlowsk TM. Immunological disturbances in Good's syndrome. Clin Invest Med (2009) 32(4):E301-6.

58. Wang CH, Chan ED, Perng CL, Chian CF, Chen CW, Perng WC, et al. Intravenous immunoglobulin replacement therapy to prevent pulmonary infection in a patient with Good's syndrome. J Microbiol Immunol Infect (2012) doi:10.1016/j.jmii.2012.09.003

59. Deener A, Mehra A, Bernstein L, Shliozberg J, Rubinstein A. Intravenous gammaglobulin treatment in HIV-1 infection. Immunol Allergy Clin North Am (2008) 28(4):851-9. doi:10.1016/j.iac.2008.06.001

60. Pastori D, Esposito A, Mezzaroma I. Immunomodulatory effects of intravenous immunoglobulins (IVIGs) in HIV-1 disease: a systematic review. Int Rev Immunol (2011) 30(1):44-66. doi:10.3109/08830185.2010.529975

61. The National Institute of Child Health and Human Developments Intravenous Immunoglobulin Study Group. Intravenous immune globulin for the prevention of bacterial infections in children with symptomatic human immunodeficiency virus infection. N Engl J Med (1991) 325(2):73-80. doi:10.1056/ NEJM199107113250201

62. Berger M. Subcutaneous administration of IgG. Immunol Allergy Clin North Am (2008) 28(4):779-802.

63. Berger M. Principles of and advances in immunoglobulin replacement therapy for primary immunodeficiency. Immunol Allergy Clin North Am (2008) 28(2):413-37. doi:10.1016/j.iac.2008.01.008

64. Gardulf A. Immunoglobulin treatment for primary antibody deficiencies: advantages of the subcutaneous route. BioDrugs (2007) 21(2):105-16. doi:10. 2165/00063030-200721020-00005

65. Gardulf A, Borte M, Ochs HD, Nicolay U, Vivaglobin Clinical Study Group. Prognostic factors for health-related quality of life in adults and children with primary antibody deficiencies receiving SCIG home therapy. Clin Immunol (2008) 126(1):81-8. doi:10.1016/j.clim.2007.06.009

66. Gardulf A, Nicolay U, Asensio O, Bernatowska E, Bock A, Carvalho BC, et al. Rapid subcutaneous IgG replacement therapy is effective and safe in children and adults with primary immunodeficiencies - a prospective, multi-national study. J Clin Immunol (2006) 26(2):177-85. doi:10.1007/s10875-006-9002-x

67. Ochs HD, Gupta S, Kiessling P, Nicolay U, Berger M, Subcutaneous IgG Study Group. Safety and efficacy of self-administered subcutaneous immunoglobulin in patients with primary immunodeficiency diseases. J Clin Immunol (2006) 26(3):265-73. doi:10.1007/s10875-006-9021-7

68. Borte M, Quinti I, Soresina A, Fernandez-Cruz E, Ritchie B, Schmidt DS, et al. Efficacy and safety of subcutaneous vivaglobin(R) replacement therapy in previously untreated patients with primary immunodeficiency: a prospective, multicenter study. J Clin Immunol (2011) 31(6):952-61. doi:10.1007/s10875-0119588-5

Conflict of Interest Statement: Carlo Agostini received research grants from CSL Behring and Baxter. The other authors declare that they have no relevant conflicts of interest.

Received: 14 October 2014; accepted: 24 November 2014; published online: 08 December 2014.

Citation: Compagno N, Malipiero G, Cinetto F and Agostini C (2014) Immunoglobulin replacement therapy in secondary hypogammaglobulinemia. Front. Immunol. 5:626. doi: 10.3389/fimmu.2014.00626

This article was submitted to Primary Immunodeficiencies, a section of the journal Frontiers in Immunology.

Copyright (c) 2014 Compagno, Malipiero, Cinetto and Agostini. This is an open-access article distributed under the terms of the Creative Commons Attribution License (CC $B Y)$. The use, distribution or reproduction in other forums is permitted, provided the original author(s) or licensor are credited and that the original publication in this journal is cited, in accordance with accepted academic practice. No use, distribution or reproduction is permitted which does not comply with these terms. 